\title{
Order please!
}

\section{How cultural framing shapes the impact of neighborhood disorder on law- and-order voting}

Jochem van Noord, Willem de Koster, and Jeroen van der Waal

\section{Published as:}

Van Noord, J., W. de Koster \& J. van der Waal. 2018. Order please! How cultural framing shapes the impact of neighborhood disorder on law-and-order voting. Political Geography 64: 73-82, DOI: 10.1016/j.polgeo.2018.04.001

\begin{abstract}
Local conditions shape voting behavior. Extant research has primarily scrutinized one specific relationship: the association between the share of ethnic minorities in a local context and voting for right-wing populist or anti-immigration parties. The electoral relevance of neighborhood disorder, another potentially salient local factor, has been unexplored, even though this social problem has received much attention in the field of criminology. We therefore assess whether neighborhood disorder underlies support for law-and-order parties. In so doing, we incorporate insights from the literature on cultural framing and theorize that the electoral relevance of neighborhood disorder is not the same for everyone, because different individuals may have different interpretations of the same local conditions. We thus hypothesize that neighborhood disorder more strongly inspires law-and-order voting among residents with an authoritarian disposition, that is, an aversion to diversity and difference and an inclination toward social conformity. Multilevel logistic regression analyses of nationally representative Dutch data (1678 Dutch natives in 180 neighborhoods) corroborate this hypothesis: while we find no overall effect of neighborhood disorder on law-and-order voting, there is evidence of a strong positive effect among residents with a very authoritarian disposition. We discuss the relevance of these results and provide suggestions for further research.
\end{abstract}

\section{Keywords}

Authoritarianism, cultural framing, neighborhood disorder, law-and-order voting, voting behavior 


\section{INTRODUCTION}

Local contexts matter for voting behavior (Evans, Arzheimer, Campbell, \& Cowley, 2017; Fieldhouse, Shryane, \& Pickles, 2007; Johnston \& Pattie, 2006; Scala, Johnson, \& Rogers, 2015). Various studies have assessed how neighborhood conditions relate to support for parties with a strong law-and-order agenda, mostly right-wing, populist and anti-immigration parties. These studies have shown that such parties benefit electorally from both a greater presence of ethnic minorities and higher local crime rates (e.g. Coffé, Heyndels, \& Vermeir, 2007; Dinas \& Van Spanje, 2011; Rydgren \& Ruth, 2011; Savelkoul, Laméris, \& Tolsma, 2017). However, the local characteristics that may inspire support for law-and-order parties not only include crime and ethnic diversity, but also social and physical disorder, which is an adverse local condition that has received ample attention in criminological research (Skogan, 1990; Sampson, 2012), but has been understudied in relation to vote choice. As neighborhood disorder can be particularly worrying for local residents (Ross \& Mirowsky, 1999), it may well drive them toward law-and-order voting in an attempt to restore social order (Fyfe, 1995).

We add to the literature in three ways. First, we assess whether there is indeed a positive relationship between neighborhood disorder and law-and-order voting. Second, in so doing, we adopt a multilevel approach using data on individuals nested in neighborhoods. Research on ethnic minority shares and voting for radical right-wing parties has typically utilized either aggregate macro-level data or micro-level data on individuals nested in large geographical units, such as countries, regions, or municipalities (for an overview, see Savelkoul et al., 2017: 210). While macro-level approaches are vulnerable to ecological fallacies, studies on local conditions and vote choice that do include individual-level data commonly do not focus on the contextual level that is likely to matter most: the neighborhood (exceptions are Dinas \& Van Spanje, 2011; Savelkoul et al., 2017). Third, our focus on individuals nested in neighborhoods is not only important from a methodological point of 
view, but also from a theoretical perspective. Previous research on the role of crime and immigration in anti-immigration voting (Dinas \& Van Spanje, 2011) suggests that the effects of neighborhood characteristics on vote choice are not universal. Inspired by research in communication science, cultural sociology and political science, we theorize that this is because individuals' cultural framing shapes the impact of neighborhood disorder on a preference for law-and-order parties. This would mean that groups with different attitudinal dispositions react differently to the same neighborhood conditions. Therefore, we test whether the impact of neighborhood disorder on law-and-order voting is stronger among those characterized by a higher level of authoritarianism, that is, a stronger preference for social conformity and a dislike of difference and diversity (Stenner, 2005; Velez \& Lavine, 2017).

To scrutinize the above, we apply logistic multilevel models to Dutch survey data that contain information on individuals and the neighborhoods in which they reside (the first wave of the NEtherlands Longitudinal Lifecourse Survey (NELLS); De Graaf, Kalmijn, Kraaykamp, \& Monden, 2010a). To put our analysis in context, note that the Dutch electoral system is highly proportional, resulting in a multi-party parliament (Lijphart, 2012). With a voter turnout ranging from 74.6 to 80.4 per cent during the last four parliamentary elections, each of its 150 seats roughly represents 70,000 voters. The Dutch electoral system therefore provides a fertile breeding ground for the emergence of new parties: from the 1950s onwards, dozens of new parties entered parliament (Beyens et al., 2016). Since 2006, the two parties with the strongest law-and-order profile - Geert Wilders's right-wing populist party Partij voor de Vrijheid (PVV) and the liberal-conservative Volkspartij voor Vrijheid en Democratie (VVD) have been substantially represented. During the parliamentary elections that were held in 2010, briefly after the NELLS data collection, these parties gained 24 and 31 seats, respectively. 
In our analyses, we focus on Dutch natives only, because law-and-order parties are typically found on the right wing of the political spectrum and tend to take a conservative stance regarding ethnic diversity and immigration (Burscher, Van Spanje, De Vreese, 2015; Van der Brug, 2004). This is in line with previous research discussed above on the electoral relevance of local conditions.

Our analyses indicate that there is no overall impact of neighborhood disorder on lawand-order voting. However, in line with theorizing on the importance of cultural framing, we find that disorder does inspire law-and-order voting among Dutch natives with an authoritarian disposition. In the concluding section, we discuss the implications of these findings and provide suggestions for future research.

\section{NEIGHBORHOOD DISORDER, CULTURAL FRAMING, AND LAW-AND-ORDER}

\section{VOTING}

The problem of neighborhood disorder

The issue of neighborhood disorder is commonly considered to be of great societal importance. Indeed, policymakers and politicians have been inspired for decades by broken windows theory (Wilson \& Kelling, 1982), which holds that social and physical disorder ranging from noise and the use of alcohol and drugs in public areas to graffiti painted on buildings and litter on the streets - should be fiercely combated, because persistent disorder would provide a fertile breeding ground for more serious crimes. Herbert (2001) observes the widespread popularity of this theory among politicians and reviews research indicating that public attitudes on these issues are influenced by political elites (2001: 456-457). Against this background, it is likely that local residents are concerned by instances of disorder in their neighborhoods; negative personal experiences with disorder may be amplified in a political 
context that strongly emphasizes this issue. This is also the case in the Netherlands, where clean and well-kept public spaces play a crucial role in government policies (Lub, 2013).

Although very few parties advocate social and physical disorder, concerns about this issue might still inspire law-and-order voting, as law-and-order parties are particularly vocal when it comes to counteracting disturbances to the social order (Fyfe, 1995). These parties do not just focus on measures in the legal domain, such as longer and stiffer sentences: 'penalization can be understood as being part of a right-authoritarian politico-cultural backlash aimed at restoring order in the nation' (De Koster, Van der Waal, Achterberg, \& Houtman, 2008: 730; cf. Fyfe, 1995). As such, it is plausible that residents who are troubled by disorder in their neighborhood turn to law-and-order parties in order to alleviate the problems they experience. We therefore hypothesize that neighborhood disorder is positively related to voting for law-and-order parties (Hypothesis 1).

\section{$\underline{\text { Authoritarianism as a cultural frame }}$}

The above implicitly assumes that neighborhood disorder inspires law-and-order voting in the same way among all residents. This assumption may not be valid. As Harcourt notes in his critique of broken windows theory, 'There may not be such a coherent message attached to order and disorder. On close examination, the meaning of order and disorder may not be as stable and fixed as the order-maintenance approach suggests' (2001: 18). This suggests that the same indications of local disorder may be interpreted differently by different neighborhood residents, inspiring different responses. That neighborhood characteristics might be differently related to voting behavior among different segments of the public is also suggested in a study by Dinas and Van Spanje (2011), which indicates that the electoral relevance of crime and immigration rates is particularly strong for individuals who take tough policy stances on these issues. 
This empirical finding resonates with insights on the relevance of cultural frames. The reason why the influence of neighborhood characteristics on voting behavior may not be universal is that the same neighborhood conditions can be framed differently by groups with different attitudinal dispositions. More broadly speaking, the literature in communication science, cultural sociology and political science emphasizes that cultural frames are crucial for understanding how individuals interpret and react to social reality. Here, frames are understood as 'principles of selection, emphasis and presentation composed of little tacit theories about what exists, what happens, and what matters' (Gitlin, 1980: 6). Different frames underlie different interpretations of everyday life: 'every opinion is a marriage of information and predisposition: information to form a mental picture of a given issue, and predisposition to motivate some conclusion about it' (Zaller, 1992: 6). These cultural frames differ across social groups: 'some will be culturally predisposed to accept certain information readily, or to reach a positive conclusion about it, whereas others will find the same information problematic and will discard it or reach a negative conclusion' (De Koster, Achterberg, \& Ivanova, 2016: 1531).

The relevance of cultural frames of interpretation is commonly emphasized in studies focusing on media texts (Hall, 1974, Scheufele, 1999), and has been corroborated in research on the differential effects of information provision on attitudes. Studies indicate that the same information has different consequences: it leads to more acceptance of new technologies or government policies by some citizens, but not others, depending on their cultural dispositions (e.g. Achterberg, 2014; De Koster et al., 2016). Given the origins of theorizing on cultural framing, which are rooted in the interpretation of everyday life (Goffman, 1974), it can plausibly be extended to the interpretation of the neighborhood circumstances central to the present study. As such, the focus is not on information received from the media or institutional experts, but on the different ways in which people may interpret characteristics of 
their neighborhood. Indeed, research on the implications of ethnic neighborhood diversity and interethnic neighborhood contacts demonstrates that their effects on opinions toward immigrants and ethnic minorities is moderated by the dispositions of the residents involved (Manevska, Achterberg, \& Houtman, 2017; Van Assche, Roets, Dhont, \& Van Hiel, 2014). Velez and Lavine (2017: 520) argue that 'the same diverse environment that some celebrate as a multicultural melting pot may be viewed by others as a tangle of squabbling nationalities or a threat to the social order', and convincingly demonstrate that these different interpretations are related to the extent to which residents have an authoritarian disposition (that is, the extent to which they have a preference for social conformity and a dislike of difference and diversity). The importance of authoritarianism as a moderator is also emphasized by other research on interethnic attitudes (Manevska \& Achterberg, 2013; Stenner, 2005; Van Assche et al., 2014), and it may well be extended to the impact of neighborhood disorder on law-and-order voting.

Authoritarianism is a disposition that stresses the importance of a rigid social order and is primarily driven by a view of the world as highly threatening (Adorno, Frenkel-Brunswik, Levinson, \& Nevitt, 1950; Feldman \& Stenner, 1997; Van Assche et al., 2014). Threats to or violations of this order are considered to be problematic and should thus be prevented or at least punished harshly. Authoritarians thus have a low tolerance for non-conformity (Elchardus \& Spruyt, 2012; Velez \& Lavine, 2017). Authoritarianism is regarded as a general social-ideological attitude that is of central importance in the socio-cultural political dimension that has increased in salience in the political field in Western countries (Achterberg \& Houtman, 2009; Elchardus \& Spruyt, 2012; Stubager, 2010).

While research indicates that authoritarian individuals are more likely to vote for lawand-order parties (De Koster, Achterberg, \& Van der Waal, 2013; Lubbers \& Scheepers, 2000), the above suggests that its relevance is broader than this direct effect. We expect 
authoritarianism to shape the relationship between neighborhood disorder and law-and-order voting. Given their emphasis on conformity, dislike of difference and diversity, and preference for severe, punitive measures, it is likely that neighborhood disorder inspires authoritarians to vote for law-and-order parties. This is not only because the agenda of these parties matches their emphasis on strict measures as a solution to social problems, but also because they are most likely to experience indications of neighborhood disorder as a pressing social problem. While non-authoritarian residents may be quite indifferent to litter and noise and may even like local graffiti, their authoritarian counterparts are more likely to interpret these local phenomena as troubling signs of disorder in need of a solution. We therefore hypothesize that the positive relationship between neighborhood disorder and voting for lawand-order parties is stronger among residents with a more authoritarian disposition (Hypothesis 2). Technically speaking, we expect there to be a positive interaction effect of neighborhood disorder and individual-level authoritarianism on voting for law-and-order parties.

\section{DATA AND MEASURES}

We utilize the first wave of the NEtherlands Longitudinal Lifecourse Survey (NELLS; De Graaf et al., 2010a). The response rate of $52 \%$ is common for face-to-face surveys in the Netherlands (De Graaf, Kalmijn, Kraaykamp, \& Monden, 2010b). Respondents were selected through a stratified (by degree of urbanization and region) sample of Dutch municipalities (including the four largest cities: Amsterdam, The Hague, Rotterdam, and Utrecht). The dataset has a multilevel structure (individuals nested in neighborhoods) that is well-suited for the testing of our hypotheses. ${ }^{1}$ The analyses used for testing our hypotheses include native Dutch individuals between the ages of 18-47 (with 18 being the voting age and 47 the

\footnotetext{
${ }^{1}$ The neighborhood level consists of districts (wijken) classified by Statistics Netherlands. On average, these have approximately 6500 residents.
} 
maximum age in the dataset). ${ }^{2}$ After listwise deletion based on all the variables operationalized below, 1678 individuals in 180 neighborhoods are included in the analyses.

The dependent variable is voting for law-and-order parties. We recoded the answers on the item asking respondents 'what is your preferred political party?' to create a variable measuring whether the respondent favors a party that emphasizes law-and-order (coded 1), or one of the other parties (coded 0). We used data from the widely used Comparative Manifesto Project (CMP; Volkens et al., 2015) to identify which parties qualify as law-and-order parties. Through content analyses of party manifestos, the CMP gathered data on the stances of political parties on various issues. The dataset indicates, per party, per election, what percentage of a party's manifesto is dedicated to a particular issue. For each party, we took the mean of the standardized scores on the measure for 'Favourable mentions of strict law enforcement, and tougher actions against domestic crime' (Volkens et al., 2015: 19) for the elections of 2003, 2006, and 2010. This is because voters might not base their assessment of a party's stance solely on the most recent election. Although the 2010 election was held briefly after the data collection (which mainly took place in 2009), we included it to account for the (smaller) emphasis parties might put on law-and-order issues in the wake of the financial and economic crises of 2008. Figure 1 depicts these scores, recoded to a 1-10 range. Two parties stand out: only the Liberal Conservatives (VVD) and Geert Wilders' Party for Freedom (PVV) deviate from the mean by more than one standard deviation (the z-scores are 1.11 and 2.37, respectively). We therefore coded these two parties as law-and-order parties in the dichotomous law-and-order variable.

Some background information on these parties indicates that the coding of these parties as law-and-order parties is valid. The PVV was officially established in 2006 by Geert Wilders (Vossen, 2011), who still leads the party. It had its greatest electoral successes in

\footnotetext{
${ }^{2}$ Following the widely used definition of Statistics Netherlands, a person is classified as native Dutch if both their parents were born in the Netherlands.
} 
2010 and 2017, when it managed to gain 24 and 20 seats in parliament, respectively. While the PVV is most well-known for its explicit anti-Islam agenda (Daenekindt et al., 2017a; Vossen, 2013), this is accompanied by a punitive law-and-order programme. The 'criminality plan' on its website claims that 'the Netherlands yearns for tough action on crime', to be realised by, e.g., a “"zero tolerance”-policy and considerably stricter sentencing (...); very high minimum sentences and a substantial increase of maximum sentences (...); an austere prison regime'. In addition: 'criminals need to perform services dressed in striped suits (...); and pay for the costs of their legal process and incarceration, for which all their financial resources need to be exhausted.' ${ }^{3}$ The liberal-conservative VVD was founded in 1948. Unlike the PVV, which does not embrace right-wing economic stances (Grande, 2012), the VVD is well-known for its economically conservative agenda (Kriesi, 2012). Law-and-order issues figured prominently in its election campaigns, with billboards promising 'more punishment and less sympathy for criminals', and stating, 'from now on for everyone who deserves punishment: punishment'. The section on 'safety' on the VVD's website, furthermore, claims 'we strike hard at criminality (...) [and] every criminal in the Netherlands needs to know that sooner or later he will get caught (...). We want tougher sentences for murder and manslaughter. And early release should not be automatically applied.' ${ }^{4}$

\section{[FIGURE 1 ABOUT HERE]}

The dataset includes seven questionnaire items concerning neighborhood disorder that closely resemble common disorder measures (Ross \& Mirowsky, 1999), with answer categories ranging from 1 ('(almost) never') to 3 ('frequently'). These are:

\footnotetext{
${ }^{3}$ Source https://pvv.nl/index.php/component/content/article.html?id=197:criminaliteitsplan-pvv-gepresenteerd [accessed November 27, 2017; our translation from Dutch].

${ }^{4}$ Source https://www.vvd.nl/pijlers/veiligheid/; https://www.vvd.nl/standpunten/criminaliteit/; https://www.vvd.nl/standpunten/straf/ [accessed November 27, 2017; our translation from Dutch].
} 
Does the following ever happen in your neighborhood?

1. Defacing of walls or buildings.

2. Disturbances by groups of youths.

3. Damage to or destruction of public spaces.

4. Noise (by local residents).

5. Litter, dog poo in the streets.

6. Nuisance through alcohol and drug use.

7. Disruptive traffic behavior (speeding, reckless driving, scooters/cars on sidewalk, etc.). A principal component analysis of all the respondents showed that all seven items measure one underlying dimension (Eigenvalue: 3.08; explained variance: 0.44 ). Together, these form a reliable scale for perceived neighborhood disorder (Cronbach's alpha $=0.78)$. When this individual-level perceived disorder indicator is aggregated to the neighborhood level, it provides a useful and adequate measure of neighborhood disorder.

First of all, constraints in terms of time and financial resources mean that the major alternative to survey-based assessments of neighborhood disorder, Systematic Social Observation (SSO) of public spaces, is not feasible for a nationally representative research such as ours. With SSO, neighborhood characteristics are coded by the research team, based on either direct observations or video tapes of the environment. While this may seem promising, a 'major limitation' is that this method is 'labor-intensive and very costly' (Skogan, 2015: 474), which is most likely the reason why SSO has been used in studies of single cities (e.g., Sampson \& Raudenbush, 1999), but not in large-scale, nationally representative studies.

Second, there is ample empirical evidence for substantial congruence between such measures of neighborhood disorder and those based on survey responses (for an overview, see Hipp, 2007: 676). 
Third, various scholars emphasize that residents' evaluations of neighborhood disorder are by no means inferior to assessments made by researchers. Skogan (2015: 473) notes that 'Surveys draw upon the awareness of local knowledgeables, people who live in the area, and rely on them as observers of the local scene.' As Hipp stresses, this 'raises the question of why we might expect a trained observer viewing a neighborhood at one point in time to provide a more accurate assessment than would the residents living in the neighborhood' (2007: 676). He rightly argues that it is likely that intersubjective survey responses are more valid: 'Properly measuring physical disorder would require observations over a long period of time and somehow weighting the proportion of time that such physical disorder exists. Again, it seems likely that residents of a neighborhood are better able to do this than are trained observers viewing the neighborhood at one point in time.' (Hipp, 2007: 676). This resonates with the influential work of Ross and Mirowsky (1999: 414-415): 'Because both researcher and resident assessments are reports of what they observe, however, it is not the case that the first is more objective. One is an outsider's subjective view, and the other is a resident's. Furthermore, the construct validity of respondents' assessments is typically higher than those of the researchers $(\ldots)$ presumably because residents have more experience with conditions in their neighborhood and can describe them at least as well as an outsider.'

Fourth, in a recent review of research on neighborhood disorder, Skogan (2015) concludes that such individual perceptions of neighborhood disorder have a high internal consistency at the neighborhood level. That is, despite the fact that individuals may react differently to signs of disorder, their perceptions of the presence of these signs in their neighborhood are, to a large extent, shared intersubjectively. This indicates that aggregated means of perceived disorder can be taken as an adequate measure of neighborhood disorder (see also Hipp, 2007: 676). This proves to be the case for our dataset: the reliability of unit means for neighborhoods with at least four respondents (both natives and non-natives) is 0.72 , 
which is above the recommended threshold of $0.70 .^{5}$ Accordingly, the aggregated means per neighborhood can be used as a reliable measure of neighborhood disorder. In order to aid interpretation, we recoded this context variable to a range of 1-10. Note that we have performed a robustness check (see below) in order to assess whether and how the measurement of neighborhood disorder affects our results.

The moderator variable authoritarianism is measured with five items, which capture it as an aversion to indications of difference and diversity that could disturb a rigid, homogenous social order, and the associated desire for harsh punishments. ${ }^{6}$

1. It is better for a country if everyone has the same habits and traditions.

2. It is better for a country if different religious beliefs are present [reversed].

3. It is better for a country if everyone speaks the same language.

4. If a country wants to lessen tensions, immigration has to stop.

5. Do you approve or disapprove of the death penalty?

A principal component analysis reveals one underlying dimension (Eigenvalue: 2.19; explained variance: 0.44 ), and the items form a sufficiently reliable scale (Cronbach's alpha $=$ 0.65), which was recoded to a 1-10 range.

\section{$\underline{\text { Control variables }}$}

At the individual level, we control for standard socio-demographic variables: age (in years), gender (female coded 1, male 0), and marital status (in four categories, see Table 1 below). We also control for religious affiliation (dummies for 'not religious', 'Christian', and 'other') and attendance at religious services (ranging from 1, 'never' through 7, 'several times per

\footnotetext{
${ }^{5}$ Calculated as (between group mean square - within group mean square) / between group mean square (see Vogus \& Sutcliffe, 2007: 50; see also LeBreton \& Senter, 2008: 823-824).

${ }^{6}$ The first four items have five answer categories, ranging from 'strongly agree' to 'strongly disagree'. These were recoded, so that higher scores indicate more authoritarian views. The fifth item has four answer categories, ranging from 'always wrong' to 'never wrong', and was recoded to a 1-5 range.
} 
week'), because religiosity is associated with both authoritarianism and voting preferences (De Koster \& Van der Waal, 2007). We control for level of education for the same reason (measured as the number of years formally required to complete the respondent's highest attained level of education). We include the dichotomous variable homeowner (respondents living in a dwelling owned by the respondent and/or members of their household coded as 1 , those who live in a rented dwelling coded as 0) because research indicates that this is related to both attitudes and voting behavior (André, 2017). In addition, we include indicators relevant for materialist explanations of voting behavior (Coffé et al., 2007; Van Gent, Jansen, \& Smits, 2014): net monthly household income (in 16 categories, ranging from less than 150 Euros to 7000 Euros or more), and economic egalitarianism. The latter measures the respondents' attitudes toward economic equality and redistribution using the following five items: ${ }^{7}$

1. Top incomes in business are too high.

2. The government needs to minimize income differences in the Netherlands.

3. The government should increase social benefits.

4. Businesses should be required to share profits with employees.

5. The government should allow the minimum wage to rise more than other wages. A principal component analysis shows that these five items belong to one underlying dimension (Eigenvalue: 2.41; explained variance: 0.48 ) and, with the Cronbach's alpha being 0.73 , they form a reliable scale.

At the neighborhood level, we control for the share of ethnic minorities because support for parties that can be classified as law-and-order parties has been proved to be partly driven by the ethnic composition of a neighborhood (Dinas \& Van Spanje, 2011; Savelkoul et al., 2017; Van der Waal, De Koster, \& Achterberg, 2013). The local share of ethnic minorities

\footnotetext{
${ }^{7}$ With five answer categories, ranging from strongly agree to strongly disagree. These were recoded, so that higher scores indicate more egalitarian views.
} 
is measured as the percentage of non-Western, non-native residents per neighborhood, which is a variable that is included in the NELLS dataset and originates from Statistics Netherlands.

At the neighborhood level, we also take a potential economic confounder into account by controlling for the percentage of unemployment benefit recipients (from Statistic Netherlands, included in the NELLS dataset). Finally, we follow Dinas and Van Spanje (2011) and control for neighborhood-level social capital. According to a principal component analysis of all the respondents, the following items (with answer categories ranging from $1=$ 'Completely true' to $4=$ 'Not true at all') belong to one dimension (Eigenvalue: 3.49 ; explained variance: 0.58 ):

1. People in my neighborhood greet each other.

2. People in my neighborhood can be trusted.

3. People in my neighborhood get along fine.

4. People in my neighborhood know each other.

5. People in my neighborhood like to help each other.

6. People in my neighborhood would speak up if youths made trouble.

Together, these items form a reliable scale $($ Cronbach's alpha $=0.85)$ and the individual scale scores were aggregated to arrive at a measure of neighborhood-level social capital: the reliability of unit means for neighborhoods with at least four respondents (both natives and non-natives) is 0.72 , which is above the recommended value of 0.70 (Vogus \& Sutcliffe, 2007: 50).

Table 1 lists the descriptive statistics for all the variables after listwise deletion.

[TABLE 1 ABOUT HERE]

\section{$\underline{\text { RESULTS }}$}

$\underline{\text { Main analyses }}$ 
As we have a dichotomous dependent variable and data on two levels, we employ logistic multilevel regression analyses. Table 2 presents the results. Model 1 shows that disorder does not directly affect law-and-order voting. People who live in neighborhoods characterized by higher levels of disorder do not vote more often for law-and-order parties. Models 2 and 3 indicate that this finding is unaltered if the effects of the covariates are taken into account, either with (model 3) or without (model 2) the attitudinal variables economic egalitarianism and authoritarianism included in the analysis. Consequently, Hypothesis 1 is not corroborated: we found no evidence that neighborhood disorder is positively related to voting for law-andorder parties.

\section{[TABLE 2 ABOUT HERE]}

This does not imply, however, that neighborhood disorder is electorally irrelevant. After all, insights on cultural framing suggest that signs of disorder in the neighborhood may only steer residents with an authoritarian disposition toward law-and-order parties. This is hidden from view if one only focuses on the direct effect of neighborhood disorder. We therefore added the interaction between neighborhood disorder and authoritarianism in Model 3. This interaction effect proves to be statistically significant. As Brambor, Clark, and Golder (2006) emphasize, a graphical display of the underlying pattern is crucial for a correct interpretation. We therefore plotted the relationship between neighborhood disorder and the probability of voting for a law-and-order party for different levels of authoritarianism (at the mean score of 5.55 and at two standard deviations below and above the mean, respectively 2.50 and 8.61), with all the other variables fixed at their mean scores. Figure 2 portrays the results, demonstrating that there is no relationship whatsoever for people with low or medium scores on authoritarianism. Indeed, for the latter, their probability of voting for a law-and- 
order party is nearly identical for all levels of neighborhood disorder. Meanwhile, for the former, there even appears at first sight to be a slightly negative relationship between neighborhood disorder and law-and-order voting, but this relationship is not significant $(p=0.175) .{ }^{8}$ Accordingly, for these citizens, neighborhood disorder has no clear electoral consequences. Things are radically different, however, for those with an authoritarian disposition: among the people who score highly on authoritarianism, there is a very strong positive relationship between neighborhood disorder and law-and-order voting. Those with an authoritarian disposition who live in neighborhoods with the lowest level of disorder have a predicted probability of voting for a law-and-order party of 0.369 , while the probability of voting for such a party is 0.902 among people with an equally authoritarian disposition who live in neighborhoods with the highest level of disorder. This difference of 0.533 is statistically significant $(p=0.007)$. This means that our second hypothesis is corroborated: there is a positive relationship between neighborhood disorder and voting for law-and-order parties, but only among residents with an authoritarian disposition.

\section{[FIGURE 2 ABOUT HERE]}

\section{$\underline{\text { Robustness checks }}$}

We conducted various additional analyses to explore the robustness of our results.

First, we wanted to check whether the analyses were confounded by variations in local crime rates. Accordingly, we conducted an additional analysis using a measure for local crime rates taken from Statistics Netherlands. ${ }^{9}$ As crime rates at the neighborhood level were

\footnotetext{
${ }^{8}$ Calculated using the Stata package mlincom (Long \& Freese, 2014).

${ }^{9}$ Source

http://statline.cbs.nl/Statweb/publication/?DM=SLNL\&PA=83032NED\&D1=2\&D2=0,18\&D3=6,9,16,64, $70,77,80,96,105,118,120-122,141,162,171,175-176,219,229,232,254,261,278,283-$

$\underline{284,321,327,330,339,341,358,364,395 \& D 4=3-4 \& H D R=T, G 1, G 3 \& S T B=G 2 \& V W=T}$ [accessed April 7, 2017$].$
} 
unavailable, we used the crime rate per municipality instead (averaged over 2008 and 2009). This means that the dataset had a more complicated structure, with 1678 individuals nested in 180 neighborhoods nested in 35 municipalities. Three-level logistic regression analyses that included the municipal crime rate, next to all the variables included in the main analyses, indicated that our findings were robust: the municipal crime rate does not affect law-and-order voting ( $p=0.482$ ), and the relationship between neighborhood disorder and law-and-order voting is similar to the results presented above: among residents with low or medium scores on authoritarianism, there is no relationship between neighborhood disorder and law-andorder voting ( $p=0.245$ and $p=0.551$, respectively). Meanwhile, those with an authoritarian disposition are much more likely to vote for a law-and-order party if they live in the most, instead of the least, disorderly neighborhoods (a difference of $0.531 ; p=0.005$ ).

As a second robustness check, we assessed whether the extent to which the local context has a rural or urban character may have affected our main results. The NELLS dataset contains a municipality-level variable with four categories that is based on the standard classification of Statistics Netherlands. After reverse coding, higher scores indicated municipalities with a more urban character. Three-level logistic regression analyses that included the urban character of the municipality next to all the variables included in the main analyses indicated that our findings were robust. The degree to which a municipality has an urban character is not associated with law-and-order voting $(p=0.398)$, and when this association is modelled, the relationship between neighborhood disorder and law-and-order voting is similar to the results presented above: among residents with low or medium scores on authoritarianism, there is no relationship between neighborhood disorder and law-andorder voting ( $p=0.264$ and $p=0.492$, respectively). Meanwhile, also when controlling for the degree to which a municipality has an urban character, those with an authoritarian disposition

We use data on felonies (misdrijven), because these are conceptually more distinct from the disorder indicators than misdemeanors (overtredingen). 
are much more likely to vote for a law-and-order party if they live in the most, instead of the least, disorderly neighborhoods (a difference of $0.546 ; p=0.003$ ).

In a third robustness check, we distinguished between the two law-and-order parties included in our main analyses. In the above, the dependent variable was dichotomized between those who voted either PVV or VVD on the one hand and individuals preferring other parties on the other. Although the party manifesto data discussed in the section on data and measures demonstrated that both the VVD and PVV can be classified as law-and-order parties, it remains to be seen whether voters perceive them in the same way and similarly relate signs of neighborhood disorder to a preference for these parties. We therefore conducted two additional analyses: one with VVD voters versus individuals who prefer other parties (with PVV voters coded as missing), and one with PVV voters versus individuals who prefer other parties (with VVD voters coded as missing).

In both cases, this produced similar results to our main analyses. ${ }^{10}$ Unsurprisingly, support for both the VVD and PVV versus other parties is significantly related to authoritarianism $(p<0.0005$ in both cases $)$, which is in line with their law-and-order profile. In addition, both additional analyses indicate that Hypothesis 1 is not corroborated: there is no evidence for a direct effect of neighborhood disorder on law-and-order voting ( $p=0.266$ and $p=0.976$, respectively). Moreover, the results of both analyses are in line with Hypothesis 2 , suggesting that neighborhood disorder only inspires law-and-order voting among residents with an authoritarian disposition. Just as in our main analyses, we found that neighborhood disorder is not associated with voting for either the VVD or PVV among those with low or medium scores on authoritarianism. In contrast, we found that the level of neighborhood

\footnotetext{
${ }^{10}$ This robustness check focuses on the results that are relevant given our research question, theory and hypotheses. In addition, they shed light on the effects of income (positive) and economic egalitarianism (negative) in our main analyses. These can be solely attributed to VVD-voting. In the separate analyses, there is no significant effect of these variables ( $p=0.997$ and $p=0.185$, respectively) on PVV-voting, whereas VVDvoting is driven by both income $(p=0.023)$ and aversion to economic egalitarianism $(p<0.0005)$. This is line with the fact that the VVD has a much more right-wing economic agenda than the PVV (Grande, 2012; Kriesi, 2012).
} 
disorder strongly affects having a preference for the VVD instead of other parties among residents with an authoritarian disposition: the predicted probability of voting for the VVD among this group is 0.067 for those living in the neighborhoods with the lowest level of disorder and 0.938 for authoritarians living in the most disorderly neighborhoods. This difference of 0.871 is statistically significant $(p<0.0005)$. In our analysis comparing PVV voting with voting for other parties, a similar pattern emerged: residents with an authoritarian disposition have a predicted probability of 0.276 when it comes to voting for the PVV in the most orderly neighborhoods and 0.786 in the most disorderly neighborhoods. Note, however, that the latter difference of 0.510 is not statistically significant $(p=0.169)$. Accordingly, Hypothesis 2 is unequivocally corroborated when it comes to VVD, but not PVV, voting. Why this is the case remains an open question. One possibility is that voters concerned about neighborhood disorder perceive the VVD, which has been part of various government coalitions, as being more capable of solving the problems they face than the right-wing populist PVV, which lacks experience in government. In addition, the VVD has ran in local elections in just about every Dutch municipality for decades, while the first time the PVV participated in local elections was in 2010, in merely two cities. Citizens might therefore perceive the VVD as more invested in battling local problems such as neighborhood disorder, even during national elections. Another explanation may be that media representations of the PVV strongly emphasize its anti-Islam agenda (cf. Daenekindt et al., 2017a), which may decrease the likelihood that citizens who are concerned by other social issues, such as local disorder, turn to the PVV for solving their problems.

In a fourth robustness check, we assessed whether our operationalization of neighborhood disorder by means of aggregated individual-level perceptions of disorder affected our findings. Our main analyses focus on neighborhoods for which the level of disorder was measured by aggregating at least four individual-level scores. Figure 3 indicates 
how the reliability of the measure of neighborhood disorder varies with the minimum number of residents used for calculating this score.

\section{[FIGURE 3 ABOUT HERE]}

Figure 3 first shows that a more lenient criterion of a minimum of 3 instead of 4 respondents per neighborhood also produces a neighborhood-level measure that is sufficiently reliable (0.71). If this measure is applied instead of the one used in our main analyses, we reach the same conclusions with respect to our hypotheses. There is no evidence for an effect of neighborhood disorder on law-and-order voting among respondents with low $(p=0.401)$ or medium ( $p=0.357$ ) levels of authoritarianism, while neighborhood disorder does positively impact law-and-order voting among respondents characterized by high levels of authoritarianism: in the latter group, the predicted probability of voting for a law-and-order party is 0.553 higher $(p=0.006)$ in the most disorderly neighborhoods compared to the least disorderly ones.

In addition, Figure 3 shows that stricter criteria (that is, higher minimum numbers of respondents per neighborhood in assessing neighborhood disorder) result in even higher reliability scores, but that these come at the expense of the number of neighborhoods that can be included in the analyses. In order to further assess the robustness of our results, we have redone our multilevel analyses with measures of neighborhood disorder based on, respectively, a minimum of 6,8 , and 10 respondents per neighborhood. Note that the steep decline in the number of neighborhoods shown in Figure 3 indicates a substantial loss of statistical power in these analyses. As our hypotheses predict the direction of the effects, we therefore use one-sided tests. The overall picture is similar to that in our main analyses. Regardless of the criterion used, there is no evidence at all for an effect of neighborhood 
disorder on law-and-order voting among respondents with low or medium levels of authoritarianism. In contrast, neighborhood disorder proves positively associated with lawand-order voting among residents with an authoritarian disposition when the criterion of a minimum of 6 respondents per neighborhood is used: the difference in the predicted probability of law-and-order voting between the most and least disorderly neighborhoods is 0.408 ( $p=0.043$ ). If the two even stricter criterions are applied, this difference remains substantial ( 0.361 and 0.341 , respectively), but is only significant at the ten-percent level ( $p=0.081$ and $p=0.061$, respectively).

In a fifth robustness check, we explored the possibility that residents' level of authoritarianism may have affected the individual-level perceptions of disorder that were aggregated in creating our measure of neighborhood disorder. We have carried out three additional multilevel analyses, in which individual-level perceived disorder is included as a dependent variable. These analyses show that authoritarianism is not related to perceived disorder at the individual level. The effect of authoritarianism proves to be far from significant in models that include as independent variables: 1) only authoritarianism $(p=0.724) ; 2)$ authoritarianism and all socio-demographic controls included in our main analyses $(p=0.650)$; and 3 ) authoritarianism and all control variables (that is, sociodemographic controls as well as the attitudinal control variable economic egalitarianism) $(p=0.761)$. Hence, individual-level perceptions of disorder do not appear to be affected by residents' level of authoritarianism.

In a sixth robustness check, we checked whether authoritarian residents of neighborhoods with low levels of disorder differ from authoritarian residents of disorderly neighborhoods, which might be the case due to constrained choices of residence. We have carried out two additional multilevel analyses, one for respondents living in neighborhoods with a level of disorder below the median and one for those in neighborhoods with a disorder 
level above the median. In these analyses, authoritarianism is the dependent variable and all individual-level control variables are included as independent variables. Figure 4 presents an overview of the association of these control variables on the one hand and authoritarianism on the other.

\section{[FIGURE 4 ABOUT HERE]}

The results depicted in Figure 4 provide no evidence that constrained choices of residence have resulted in differences between authoritarian respondents in orderly and disorderly neighborhoods that may have affected our main results. Z-tests (Paternoster, Brame, Mazerolle, \& Piquero, 1998) indicate that the differences across both neighborhood types are not statistically significant. ${ }^{11}$ The only exception is the association between economic egalitarianism and authoritarianism. However, the fact that this association is significantly weaker $(p<0.05)$ in disorderly neighborhoods is at odds with the suggestion that authoritarian respondents in these underprivileged neighborhoods differ from authoritarians in orderly neighborhoods due to constrained residential choices. After all, if constrained residential choices were in play, the association between authoritarianism and a preference for economic equality and redistribution would be stronger instead of weaker in more disorderly neighborhoods. ${ }^{12}$

\footnotetext{
${ }^{11}$ We have also conducted these z-tests with other reference categories for our dummy variables. This did not affect our conclusions.

${ }^{12}$ A referee suggested that, in addition to our control variables, downward social mobility might be relevant. Therefore, we conducted additional analyses, in which we measured social mobility in the same way as recent research that uses the same NELLS data for answering other substantive questions (Daenekindt et al., 2017b; Van der Waal et al., 2017). Diagonal Reference Models (DRMs), which are required for disentangling the effect of social mobility from the effects of the social positions of origin and destination (Sobel, 1981, 1985; Van der Waal et al., 2017), are not available in a multilevel framework. Therefore, we used dummy variables for those who are immobile and those who are upwardly mobile (reference category: downwardly mobile). These were included in two multilevel models also containing all other individual-level control variables to assess whether these differently affect authoritarianism in disorderly neighborhoods as compared to orderly neighborhoods. No significant effects were found: the $p$-values of the dummies for immobile and upwardly mobile are 0.210 and 0.685 in neighborhoods with a low level of disorder and 0.077 and 0.123 in neighborhoods with a high level of disorder. Therefore, there is no evidence that authoritarianism is affected by downward social mobility.
} 


\section{CONCLUSION AND DISCUSSION}

While there is a growing body of research that scrutinizes whether and how neighborhood conditions affect voting behavior, the relationship between the potentially pressing problem of neighborhood disorder and law-and-order voting has remained unexplored. In the present study, we found no evidence of an overall relationship between signs of neighborhood disorder and a preference for law-and-order parties. However, this certainly does not mean that citizens are indifferent to signs of neighborhood disorder. Consistent with theorizing on cultural framing, we found that the association between neighborhood disorder and law-andorder voting depends on the extent to which residents have an authoritarian disposition. Among those with a strong aversion to difference and diversity and a strong preference for a rigid social order, a disorderly neighborhood inspires support for law-and-order parties. Citizens with an authoritarian disposition seem to be troubled by a disorderly residential environment and turn to law-and-order parties to solve this problem. In contrast to this call for order, neighborhood disorder does not inspire a law-and-order vote among citizens who are not characterized by a strongly authoritarian disposition. Individuals who are less strongly attached to a rigid, homogeneous social order seem to be less inclined to consider signs of neighborhood disorder as a pressing social problem.

It is, of course, important to assess whether these results could be biased by the design of our study. An issue commonly considered in cross-sectional analyses of the effects of neighborhood conditions is selection bias. Could it be that our results are fully or partly due to selective migration in and out of neighborhoods? If neighborhood disorder affects decisions to move into or out of certain neighborhoods, it is likely that those most inclined to perceive disorder as a problem would avoid disorderly neighborhoods the most. This suggests that those who are most likely to turn to law-and-order parties if faced with neighborhood disorder 
may be underrepresented in disorderly neighborhoods. This means that it is unlikely that we have encountered a spurious relationship.

In addition, the size of the geographic units used to measure neighborhoods should be taken into account (Hipp, 2007). The neighborhoods assessed in this study are formally classified as districts (wijken) by Statistics Netherlands and have an average size of approximately 6500. As this is larger than a typical small-scale neighborhood, it is important to consider how this could have affected our findings. In this respect, it is relevant that American research that compares inquiries into neighborhood disorder at different levels of aggregation suggests that census tracts (which most closely resemble the units in the present study) are the most appropriate level (Hipp, 2007). Moreover, the same study indicates that using suboptimal geographical units may lead to an underestimation of effects. This implies that we have conservatively assessed the electoral relevance of neighborhood disorder.

More generally, our findings not only demonstrate the hitherto understudied electoral relevance of neighborhood disorder, but also add strength to arguments emphasizing the importance of cultural framing. Previous research has shown that effects of both information provision and local conditions do not have a universal impact on political attitudes and behaviors (Manevska \& Achterberg, 2013; Achterberg, 2014; Van Assche et al., 2014; Velez \& Lavine, 2017): effects may be large among groups with specific dispositions, but absent among others. Extant research that takes into account the moderating role of dispositions when it comes to the political implications of local conditions has mainly focused on ethnic diversity. Our research on neighborhood disorder indicates that the salience of this approach is broader than that. This suggests that local conditions that are perceived to be problematic by some may leave others indifferent or may even inspire enthusiasm among them. We therefore recommend that future studies on the political relevance of various conditions at the country, regional, municipal and neighborhood levels take the relevance of cultural framing 
into account. This may be done in quantitative analyses like the one presented here, as these are well-suited for scrutinizing cultural meanings as potentially powerful social forces (Houtman \& Achterberg, 2016). Ideally, these are supplemented by in-depth qualitative accounts, for instance informed by in-depth interviews and ethnographic fieldwork, in order to gain a more fine-grained contextualized understanding of the precise ways in which different groups make sense of social life, how this relates to structural characteristics of their social environment, and how this is relevant with respect to various forms of political action. 


\section{REFERENCES}

Achterberg, P. (2014). Knowing hydrogen and loving it too? Information provision, cultural predispositions, and support for hydrogen technology among the Dutch. Public Understanding of Science, 23(4), 445-453.

Achterberg, P., \& Houtman, D. (2009). Ideologically illogical? Why do the lower-educated Dutch display so little value coherence? Social Forces, 87(3), 1649-1670.

Adorno, T. W., Frenkel-Brunswik, E., Levinson, D. J., \& Nevitt, R. (1950). The authoritarian personality. Oxford: Harpers.

André, S. (2017). The two sides of homeownership: security and insecurity: A comparative approach to the effects of housing tenure and housing wealth on political attitudes, political behavior and subjective wellbeing. Tilburg: Tilburg University.

Beyens, S., Lucardie, P. and Deschouwer, K. (2016). The life and death of new political parties in the Low Countries. West European Politics, 39(2), 257-277.

Brambor, T., Clark, W. R., Golder, M. (2006). Understanding interaction models: Improving empirical analyses. Political Analysis, 14(1), 63-82.

Burscher, B., Van Spanje, J., \& de Vreese, C. H. (2015). Owning the issues of crime and immigration: the relation between immigration and crime news and anti-immigrant voting in 11 countries. Electoral Studies, 38, 59-69.

Coffé, H., Heyndels, B., \& Vermeir, J. (2007). Fertile grounds for extreme right-wing parties: Explaining the Vlaams Blok's electoral success. Electoral Studies, 26(1), 142-155.

Daenekindt, S., De Koster, W., \& Van der Waal, J. (2017a). How people organise cultural attitudes: cultural belief systems and the populist radical right. West European Politics, 40(4), 791-811.

Daenekindt, S., Van der Waal, J., \& De Koster, W. (2017b). Social mobility and political distrust: cults of gratitude and resentment? Acta Politica, doi: 10.1057/s41269-017-0050-4.

De Graaf, P.M., Kalmijn, M., Kraaykamp, G., \& Monden, C. (2010a). The NEtherlands Longitudinal Lifecourse Study (NELLS). Tilburg University and Radboud University Nijmegen.

De Graaf, P.M., Kalmijn, M., Kraaykamp, G., \& Monden, C. (2010b). Design and content of the NEtherlands Longitudinal Lifecourse Study (NELLS). Tilburg University and Radboud University Nijmegen.

De Koster, W., Achterberg, P., \& Ivanova, N. (2016). Reconsidering the impact of informational provision on opinions of suspended sentences in the Netherlands: The importance of cultural frames. Crime \& Delinquency, 62(11), 1528-1539.

De Koster, W., Achterberg, P., \& Van der Waal, J. (2013). The new right and the welfare state: The electoral relevance of welfare chauvinism and welfare populism in the Netherlands. International Political Science Review, 34(1), 3-20.

De Koster, W., \& Van der Waal, J. (2007). Cultural value orientations and Christian religiosity: On moral traditionalism, authoritarianism, and their implications for voting behavior. International Political Science Review, 28(4), 451-467.

De Koster, W., Van der Waal, J., Achterberg, P., \& Houtman, D. (2008). The rise of the penal state: Neo-liberalization or new political culture? The British Journal of Criminology, 48(6), 720-734.

Dinas, E., \& van Spanje, J. (2011). Crime story: The role of crime and immigration in the anti-immigration vote. Electoral Studies, 30(4), 658-671.

Elchardus, M., \& Spruyt, B. (2012). The contemporary contradictions of egalitarianism: An empirical analysis of the relationship between the old and new left/right alignments.

European Political Science Review, 4(2), 217-239. 
Evans, J., Arzheimer, K., Campbell, R., \& Cowley, P. (2017). Candidate localness and voter choice in the 2015 general election in England. Political Geography, 59, 61-71.

Feldman, S., \& Stenner, K. (1997). Perceived threat and authoritarianism. Political Psychology, 18(14), 741-770.

Fieldhouse, E., Shryane, N., \& Pickles, A. (2007). Strategic voting and constituency context: modelling party preference and vote in multiparty elections. Political Geography, 26(2), $159-178$.

Fyfe, N. R. (1995). Law and order policy and the spaces of citizenship in contemporary Britain. Political Geography, 14(2), 177-189.

Gitlin, T. (1980). The whole world is watching: Mass media in the making \& unmaking of the new left. Berkeley: University of California Press.

Goffman, E. (1974). Frame analysis: An essay on the organization of experience. Boston: Northeastern University Press.

Grande, E. (2012) Conclusion: How much change can we observe and what does it mean? In H. Kriesi et al. (Eds.), Political conflict in Western Europe (pp. 277-301). Cambridge: Cambridge University Press.

Hall, S. (2006). Encoding/decoding. In M. G. Durham \& D. Kellner (Eds.), Media and cultural studies: Keywords (pp. 163-173). Malden, MA: Blackwell.

Harcourt, B. E. (2001). Illusion of order: The false promise of broken windows policing. Cambridge and London: Harvard University Press.

Herbert, S. (2001). Policing the contemporary city: Fixing broken windows or shoring up neoliberalism? Theoretical Criminology, 5(4), 445-466.

Hipp, J. R. (2007). Block, tract, and levels of aggregation: Neighborhood structure and crime and disorder as a case in point. American Sociological Review, 72(5), 659-680.

Houtman, D. \& Achterberg, P. (2016), Quantitative analysis in cultural sociology: Why it should be done, how it can be done. In: D. Inglis \& A.-M. Almila (Eds.), Sage Handbook of Cultural Sociology (pp. 225-236). London: Sage.

Johnston, R. J., \& Pattie, C. J. (2006). Putting voters in their place: Geography and elections in Great Britain. Oxford University Press.

Kriesi, H. (2012) Restructuring the national political space: The supply side of national electoral politics. In H. Kriesi et al. (Eds.), Political conflict in Western Europe (pp. 96150). Cambridge: Cambridge University Press.

LeBreton, J. M., \& Senter, J. L. (2008). Answers to 20 questions about interrater reliability and interrater agreement. Organizational Research Methods, 11(4), 815-852.

Lijphart, A. (2012). Patterns of democracy: Government forms and performance in thirty-six countries, 2 nd edition. New Haven: Yale University Press.

Long, J. S., \& Freese, J. (2014). Regression models for categorical dependent variables using Stata, 3rd edition. College Station, TX: Stata Press.

Lub, V. (2013). Schoon, heel en werkzaam? Een wetenschapelijke beoordeling van sociale interventies op het terrein van buurtleefbaarheid. Den Haag: Boom |Lemma.

Lubbers, M., \& Scheepers, P. (2000). Individual and contextual characteristics of the German extreme right-wing vote in the 1990s. A test of complementary theories. European Journal of Political Research, 38(1), 63-94.

Manevska, K., \& Achterberg, P. (2013). Immigration and perceived ethnic threat: Cultural capital and economic explanations. European Sociological Review, 29(3), 437-449.

Manevska, K., Achterberg, P., \& Houtman, D. (2017). Why there is less supportive evidence for contact theory than they say there is: A quantitative cultural-sociological critique. American Journal of Cultural Sociology, doi: 10.1057/s41290-017-0028-8.

Paternoster, R., Brame, R., Mazerolle, P., \& Piquero, A. (1998). Using the correct statistical test for the equality of regression coefficients. Criminology, 36(4), 859-866. 
Ross, C. E., \& Mirowsky, J. (1999). Disorder and decay: The concept and measurement of perceived neighborhood disorder. Urban Affairs Review, 34(3), 412-432.

Rydgren, J., \& Ruth, P. (2011). Voting for the radical right in Swedish municipalities: Social marginality and ethnic competition? Scandinavian Political Studies, 34(3), 202-225.

Sampson, R. J. (2012). Great American city: Chicago and the enduring neighborhood effect. Chicago; London: The University of Chicago Press.

Sampson, R. J., \& Raudenbush, S. W. (1999). Systematic social observation of public spaces: A new look at disorder in urban neighborhoods. American Journal of Sociology, 105(3), 603-651.

Savelkoul, M., Laméris, J., Tolsma, J. (2017). Neighbourhood ethnic composition and voting for the radical right in the Netherlands. The role of perceived neighbourhood threat and interethnic neighbourhood contact. European Sociological Review, 33(2), 209-224.

Scala, D. J., Johnson, K. M., \& Rogers, L. T. (2015). Red rural, blue rural? Presidential voting patterns in a changing rural America. Political Geography, 48, 108-118.

Scheufele, D. A. (1999). Framing as a theory of media effects. Journal of Communication 49(1), 103-22.

Skogan, W. (1990). Disorder and decline: Crime and the spiral of decay in American neighborhoods. New York and Toronto: The Free Press.

Skogan, W. (2015). Disorder and decline: The state of research. Journal of Research in Crime and Delinquency, 52(4), 464-485.

Sobel, M. E. (1981). Diagonal mobility models: A substantively motivated class of designs for the analysis of mobility effects. American Sociological Review, 46(6), 893-906.

Sobel, M. E. (1985). Social mobility and fertility revisited: Some new models for the analysis of the mobility effects hypothesis. American Sociological Review, 50(5), 699-712.

Stenner, K. (2005). The authoritarian dynamic. Cambridge: Cambridge University Press.

Stubager, R. (2010). The development of the education cleavage: Denmark as a critical case. West European Politics, 33(3), 505-33.

Van Assche, J., Roets, A., Dhont, K., \& Van Hiel, A. (2014). Diversity and out-group attitudes in the Netherlands: The role of authoritarianism and social threat in the neighbourhood. Journal of Ethnic and Migration Studies, 40(9), 1414-1430.

Van der Brug, W. (2004). Issue ownership and party choice. Electoral Studies, 23(2), 209233.

Van der Waal, J., Daenekindt, S., \& De Koster, W. (2017). Statistical challenges in modelling the health consequences of social mobility: The need for Diagonal Reference Models. International Journal of Public Health, 62(9), 1029-1037.

Van der Waal, J., De Koster, W., \& Achterberg, P. (2013). Ethnic segregation and radical right-wing voting in Dutch cities. Urban Affairs Review, 49(5), 748-777.

Van Gent, W. P. C., Jansen, E. F., \& Smits, J. H. F. (2014). Right-wing radical populism in city and suburbs: An electoral geography of the Partij Voor de Vrijheid in the Netherlands. Urban Studies, 51(9), 1775-1794.

Velez, Y. R., \& Lavine, H. (2017). Racial diversity and the dynamics of authoritarianism. Journal of Politics, 79(2), 519-533.

Vogus, T. J., \& Sutcliffe, K. M. (2007). The safety organizing scale: Development and validation of a behavioral measure of safety culture in hospital nursing units. Medical Care, 45(1), 46-54.

Volkens, A., Lehmann, P., Matthieß, T., Merz, N., Regel, S., \& Werner, A. (2015). The manifesto data collection. Manifesto project (MRG/CMP/MARPOR). Version 2015 a. Berlin: Wissenschaftszentrum Berlin für Sozialforschung (WZB).

Vossen, K. (2011). Classifying Wilders: The ideological development of Geert Wilders and his Party for Freedom. Politics, 31(3), 179-189. 
Vossen, K. (2013). Rondom Wilders: Portret van de PVV. Amsterdam: Boom.

Wilson, J. Q. \& Kelling, G. (1982). Broken windows: The police and neighborhood safety. Atlantic Monthly, 127(2): 29-38.

Zaller, J. (1992). The nature and origins of mass opinion. Cambridge University Press. 
Table 1: Descriptive statistics (after list-wise deletion)

\begin{tabular}{|c|c|c|c|c|c|}
\hline & $\mathrm{N}$ & Mean & SD & Min & Max \\
\hline \multicolumn{6}{|l|}{ Neighborhood-level variables } \\
\hline Disorder & 180 & 4.50 & 1.47 & 1 & 10 \\
\hline Share of non-western migrants & 180 & 14.39 & 14.68 & 0 & 85 \\
\hline Unemployment benefit receivers & 180 & 32.31 & 12.20 & 0 & 67 \\
\hline Social capital & 180 & 3.34 & .28 & 2.37 & 3.92 \\
\hline \multicolumn{6}{|l|}{ Individual level-variables } \\
\hline Authoritarianism & 1678 & 5.45 & 1.54 & 1 & 10 \\
\hline Gender $($ female $=1)$ & 1678 & 0.51 & & 0 & 1 \\
\hline Age & 1678 & 32.90 & 8.22 & 18 & 47 \\
\hline Household income & 1678 & 7.27 & 3.01 & 1 & 16 \\
\hline Homeowner & 1678 & 0.75 & & 0 & 1 \\
\hline Education & 1678 & 14.45 & 3.15 & 0 & 22 \\
\hline Attendance at religious services & 1678 & 2.06 & 1.60 & 1 & 7 \\
\hline Economic egalitarianism & 1678 & 3.26 & 0.68 & 1 & 5 \\
\hline \multicolumn{6}{|l|}{ Marital status } \\
\hline No partner & 1678 & 0.23 & & 0 & 1 \\
\hline Married and cohabiting & 1678 & 0.42 & & 0 & 1 \\
\hline Unmarried and cohabiting & 1678 & 0.22 & & 0 & 1 \\
\hline Not cohabiting (married or unmarried) & 1678 & 0.12 & & 0 & 1 \\
\hline \multicolumn{6}{|l|}{ Religious affiliation } \\
\hline Not religious & 1678 & 0.66 & & 0 & 1 \\
\hline Christian & 1678 & 0.31 & & 0 & 1 \\
\hline Other & 1678 & 0.04 & & 0 & 1 \\
\hline
\end{tabular}


Table 2: Logistic multilevel regressions on law-and-order voting

\begin{tabular}{|c|c|c|c|c|}
\hline & Model 1 & Model 2 & Model 3 & Model 4 \\
\hline Constant & $\begin{array}{l}-0.83 * * \\
(0.26)\end{array}$ & $\begin{array}{l}-3.16 \\
(1.97)\end{array}$ & $\begin{array}{l}-3.72+ \\
(2.04)\end{array}$ & $\begin{array}{l}-1.27 \\
(2.37)\end{array}$ \\
\hline Neighborhood disorder & $\begin{array}{l}-0.04 \\
(0.06)\end{array}$ & $\begin{array}{l}0.09 \\
(0.09)\end{array}$ & $\begin{array}{l}0.06 \\
(0.09)\end{array}$ & $\begin{array}{l}-0.45+ \\
(0.26)\end{array}$ \\
\hline Authoritarianism & & & $\begin{array}{l}0.56^{* * * *} \\
(0.05)\end{array}$ & $\begin{array}{l}0.19 \\
(0.19)\end{array}$ \\
\hline Disorder*Authoritarianism & & & & $\begin{array}{l}0.09 * \\
(0.04)\end{array}$ \\
\hline Gender ( $1=$ female $)$ & & $\begin{array}{l}-0.55 * * * \\
(0.12)\end{array}$ & $\begin{array}{l}-0.18 \\
(0.13)\end{array}$ & $\begin{array}{l}-0.19 \\
(0.13)\end{array}$ \\
\hline Age & & $\begin{array}{l}-0.03 * * \\
(0.01)\end{array}$ & $\begin{array}{l}-0.01 \\
(0.01)\end{array}$ & $\begin{array}{l}-0.01 \\
(0.01)\end{array}$ \\
\hline Household income & & $\begin{array}{l}0.11 * * * \\
(0.03)\end{array}$ & $\begin{array}{l}0.08 * \\
(0.03)\end{array}$ & $\begin{array}{l}0.09 * * \\
(0.03)\end{array}$ \\
\hline Homeowner & & $\begin{array}{l}0.49 * * \\
(0.16)\end{array}$ & $\begin{array}{l}0.32+ \\
(0.17)\end{array}$ & $\begin{array}{l}0.32+ \\
(0.17)\end{array}$ \\
\hline Education & & $\begin{array}{l}-0.05^{* *} \\
(0.02)\end{array}$ & $\begin{array}{l}-0.04+ \\
(0.02)\end{array}$ & $\begin{array}{l}-0.04+ \\
(0.02)\end{array}$ \\
\hline $\begin{array}{l}\text { Marital status } \\
\text { (ref.=no partner) }\end{array}$ & & & & \\
\hline Married and cohabiting & & $\begin{array}{l}-0.50^{*} \\
(0.20)\end{array}$ & $\begin{array}{l}-0.46^{*} \\
(0.22)\end{array}$ & $\begin{array}{l}-0.49 * \\
(0.22)\end{array}$ \\
\hline $\begin{array}{l}\text { Unmarried and } \\
\text { cohabiting }\end{array}$ & & $\begin{array}{l}-0.36+ \\
(0.21)\end{array}$ & $\begin{array}{l}-0.21 \\
(0.22)\end{array}$ & $\begin{array}{l}-0.23 \\
(0.22)\end{array}$ \\
\hline $\begin{array}{l}\text { Not cohabiting (married } \\
\text { or unmarried) }\end{array}$ & & $\begin{array}{l}-0.01 \\
(0.21)\end{array}$ & $\begin{array}{l}-0.15 \\
(0.22)\end{array}$ & $\begin{array}{l}-0.16 \\
(0.23)\end{array}$ \\
\hline $\begin{array}{l}\text { Religious affiliation } \\
\text { (ref=non-religious) }\end{array}$ & & & & \\
\hline Christian & & $\begin{array}{l}-0.09 \\
(0.17)\end{array}$ & $\begin{array}{l}-0.30+ \\
(0.18)\end{array}$ & $\begin{array}{l}-0.32+ \\
(0.18)\end{array}$ \\
\hline Other & & $\begin{array}{l}-0.35 \\
(0.43)\end{array}$ & $\begin{array}{l}-0.30 \\
(0.45)\end{array}$ & $\begin{array}{l}-0.32 \\
(0.45)\end{array}$ \\
\hline $\begin{array}{l}\text { Attendance at religious } \\
\text { services }\end{array}$ & & $\begin{array}{l}-0.35 * * * \\
(0.07)\end{array}$ & $\begin{array}{l}-0.36^{* * *} \\
(0.07)\end{array}$ & $\begin{array}{l}-0.35 * * * \\
(0.07)\end{array}$ \\
\hline Economic egalitarianism & & & $\begin{array}{l}-0.81 * * * \\
(0.10)\end{array}$ & $\begin{array}{l}-0.81^{* * *} \\
(0.10)\end{array}$ \\
\hline $\begin{array}{l}\text { Neighborhood share non- } \\
\text { western ethnic minorities }\end{array}$ & & $\begin{array}{l}0.00 \\
(0.01)\end{array}$ & $\begin{array}{l}0.01 \\
(0.01)\end{array}$ & $\begin{array}{l}0.01 \\
(0.01)\end{array}$ \\
\hline $\begin{array}{l}\text { Neighborhood share } \\
\text { unemployment benefit } \\
\text { receivers }\end{array}$ & & $\begin{array}{l}0.00 \\
(0.01)\end{array}$ & $\begin{array}{l}0.01 \\
(0.01)\end{array}$ & $\begin{array}{l}0.01 \\
(0.01)\end{array}$ \\
\hline $\begin{array}{l}\text { Neighborhood social } \\
\text { capital }\end{array}$ & & $\begin{array}{l}1.01^{*} \\
(0.49)\end{array}$ & $\begin{array}{l}0.79 \\
(0.50)\end{array}$ & $\begin{array}{l}0.71 \\
(0.51)\end{array}$ \\
\hline $\begin{array}{l}\text { Random effects } \\
\text { Neighborhood-level } \\
\text { variance }\end{array}$ & 0.24 & 0.17 & 0.12 & 0.00 \\
\hline
\end{tabular}




\begin{tabular}{|c|c|c|c|c|}
\hline $\begin{array}{l}\text { Random slope } \\
\text { authoritarianism }\end{array}$ & & & & 0.00 \\
\hline Log-likelihood & -965.71 & -896.55 & -786.81 & -784.19 \\
\hline$n_{\text {individual }}$ & 1678 & 1678 & 1678 & 1678 \\
\hline$n_{\text {neighborhood }}$ & 180 & 180 & 180 & 180 \\
\hline
\end{tabular}

Standard errors in parentheses; $+\mathrm{p}<0.10, * \mathrm{p}<0.05, * * \mathrm{p}<0.01, * * * \mathrm{p}<0.001$ 
Figure 1: Party scores on law-and-order

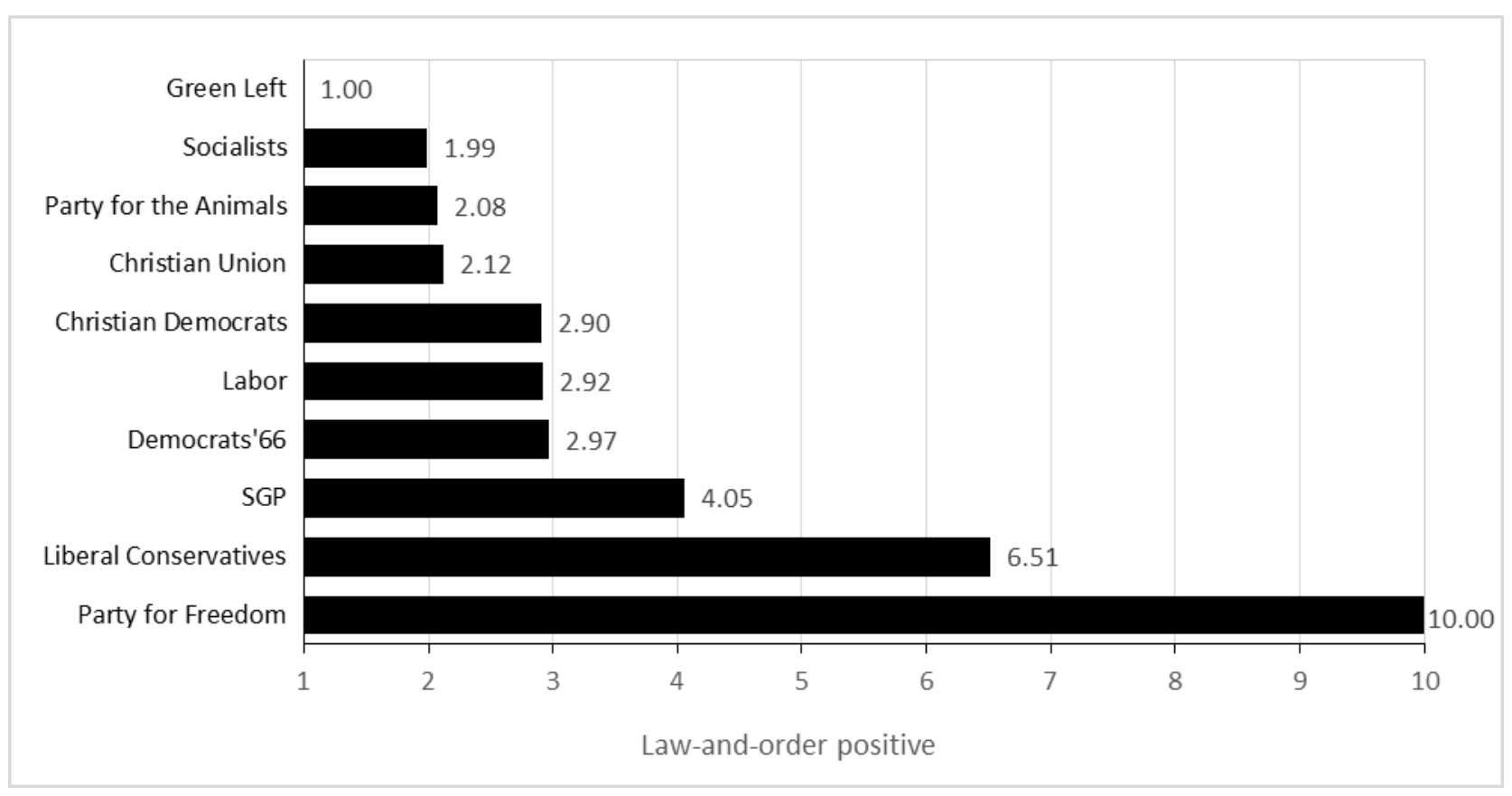

Note: scores combine standardized scores on three elections $(2003,2008$, and 2010). The means of these standardized scores were recalculated into 1-10 range. Source: calculations on CMP (Volkens et al., 2015). 
Figure 2: The relationship between neighborhood disorder and law-and-order voting, by authoritarianism

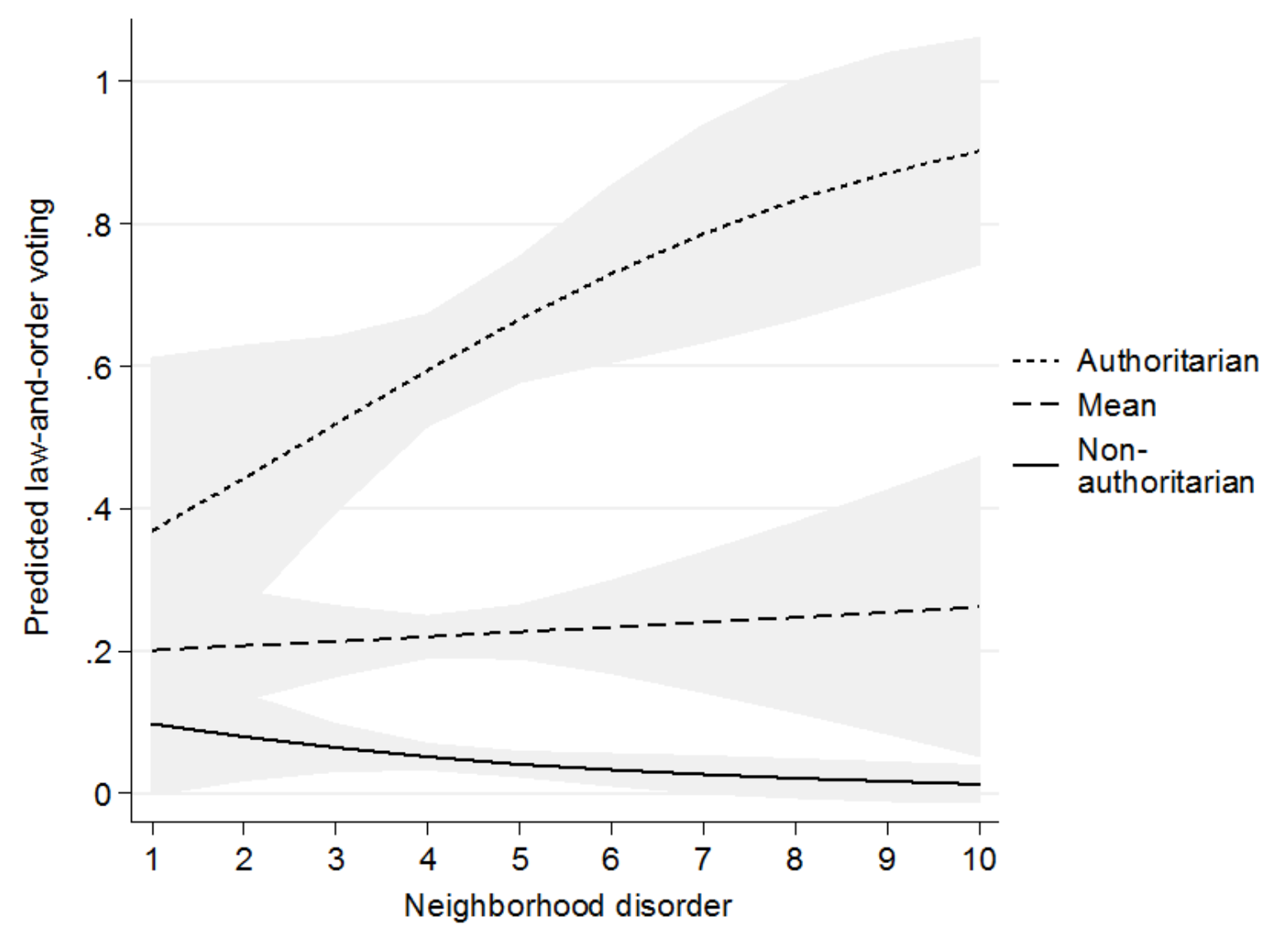

Note: shaded areas depict $95 \%$ confidence intervals. 
Figure 3: The reliability of the aggregated measure of neighborhood disorder, by the minimum number of respondents per neighborhood used when calculating this measure, and the remaining number of neighborhoods

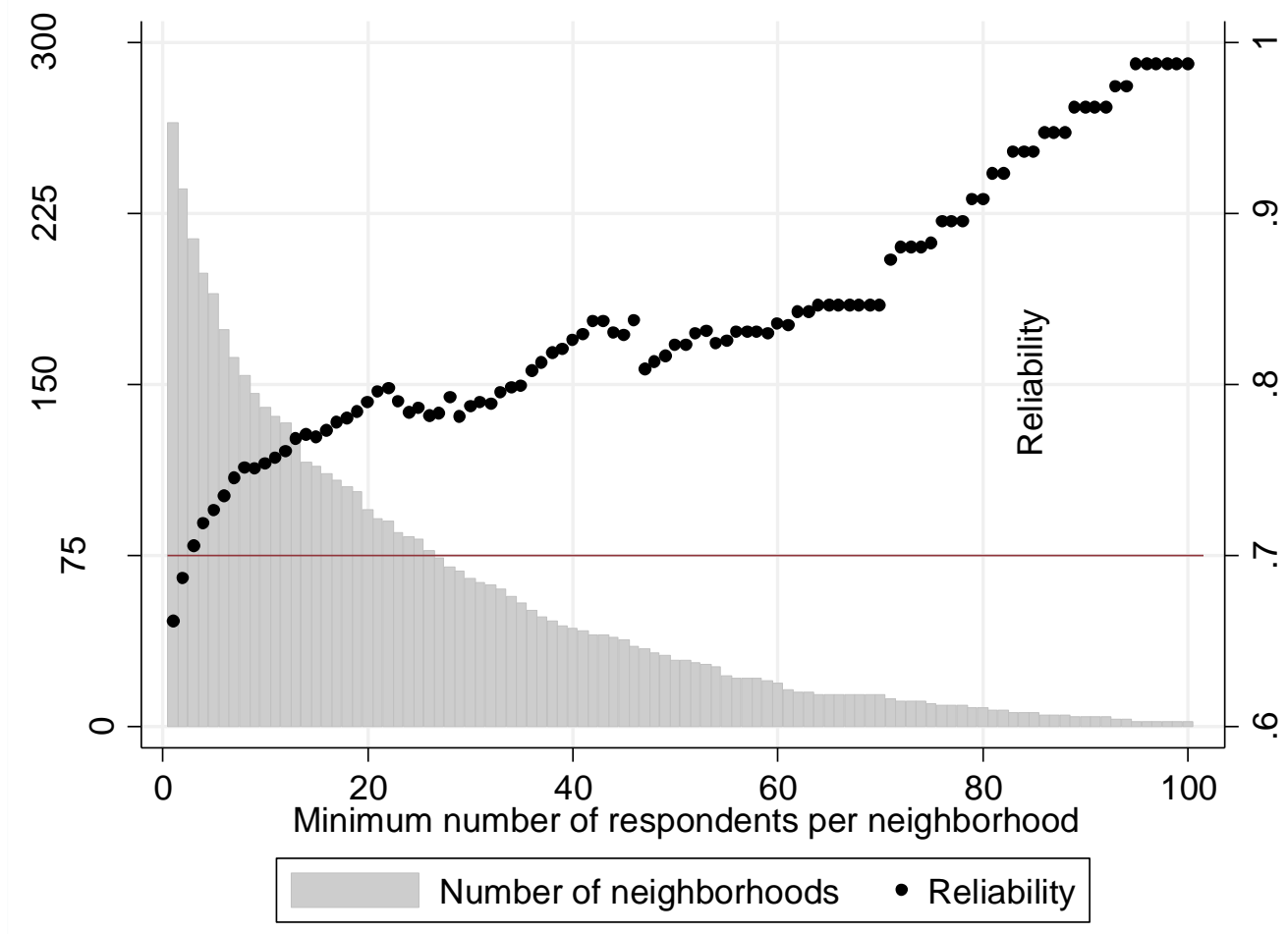


Figure 4: Associations between individual-level control variables and authoritarianism, by low/high neighborhood disorder

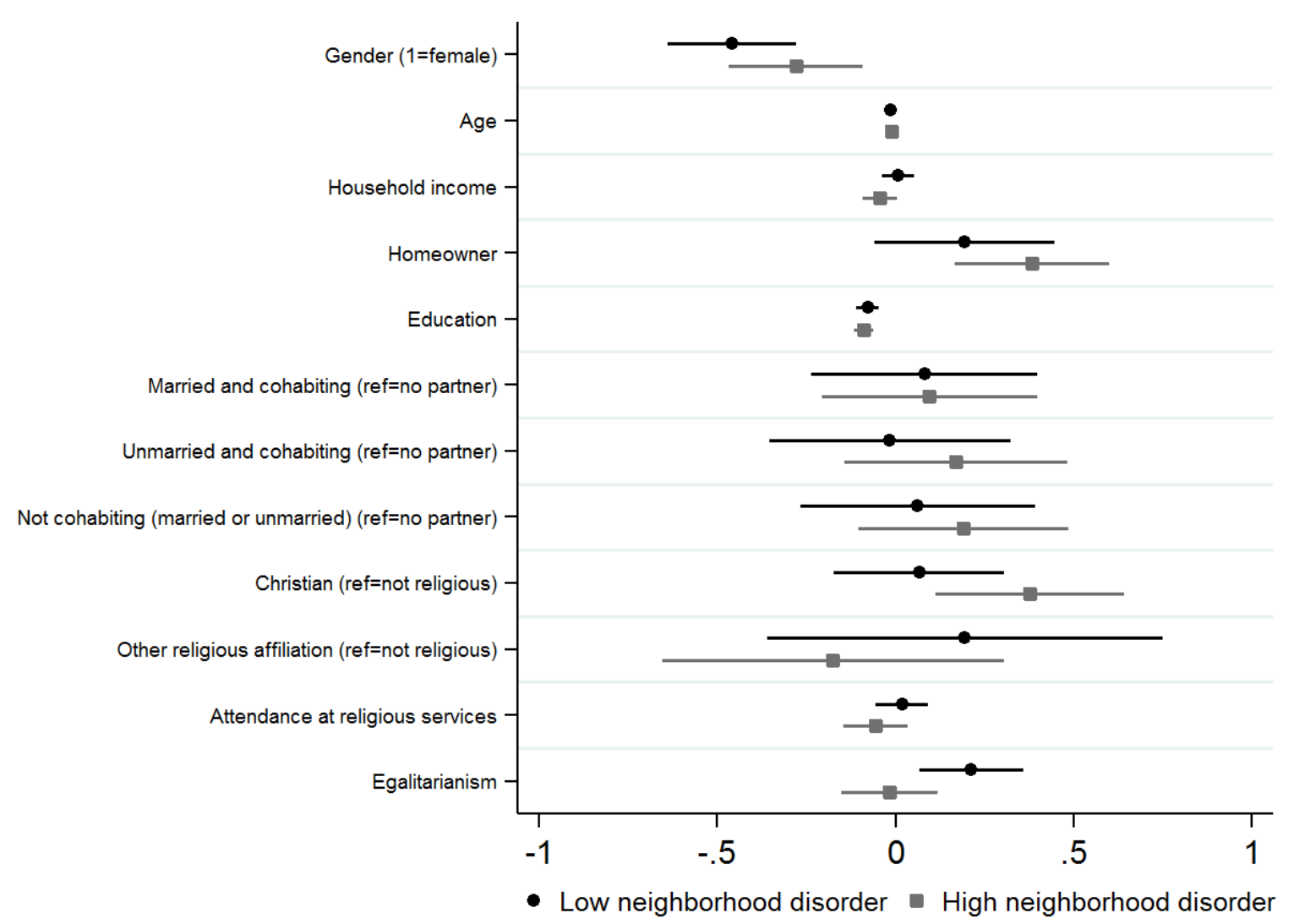

Note: Circles and squares indicate point estimates, lines depict $95 \%$ confidence intervals. 